\title{
Bajo el manto de un sarape: colores y conciliaciones internacionales a través de un objeto de arte popular
}

\author{
Marilyn Adriana Ortiz Gasca
}

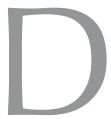
urante el otoño de 2013, el Seminario-Taller de Conservación y Restauración de Textiles de la Escuela Nacional de Conservación, Restauración y Museografía, del Instituto Nacional de Antropología e Historia (STCRT, ENCRYM-INAH), recibió un sarape festoneado proveniente del fondo reservado de la Subdirección de Etnografía del Museo Nacional de Antropología (MNA-INAH) (Figura 1); tras haber permanecido almacenado en éste durante 50 años, entonces se emprendieron los trabajos de investigación y conservación-restauración ${ }^{1}$ que conllevaron a profundizar en su materialidad e historia de vida. Los datos recabados revelaron interesantes y coloridos aspectos sobre el papel del arte popular en el ámbito de la historia de las relaciones entre México y los Estados Unidos de América (EUA) durante las primeras décadas del siglo XX, tema que, por su relevancia, es motivo de análisis en este ESCAPARATE.

\section{Introducción}

A su llegada a la ENCRyM-INAH, el textil al que me refiero contaba con limitada, pero importante, información. Los archivos del MNA-INAH declaraban que la obra ingresó en las colecciones de dicha institución en 1963, es decir, poco antes de su apertura, como donación de una familia estadounidense de apellido Morrow. El registro inicial, que la denominaba como jorongo, la destacaba al integrarla al fondo reservado del museo, un espacio destinado a los ejemplares "extraordinarios", según lo definió el doctor Ignacio Bernal (González Villarruel 2013).

Pero ¿qué pudo haber definido el carácter único de este textil? Sin duda, el ejemplar se distingue hasta nuestros días no sólo por su alta calidad de factura sino también por su peculiar diseño. Al igual que numerosos sarapes de SaltiIlo, éste fue realizado en un telar de pedales con un ligamento de tafetán. Sin

\footnotetext{
${ }^{1}$ Las estudiantes Valeria Carrillo, Marilyn Ortiz y María del Carmen Tostado Ilevaron a cabo las labores de investigación y restauración de este sarape como parte de los procesos de enseñanzaaprendizaje del STCRT, ENCRyM-INAH.
} 


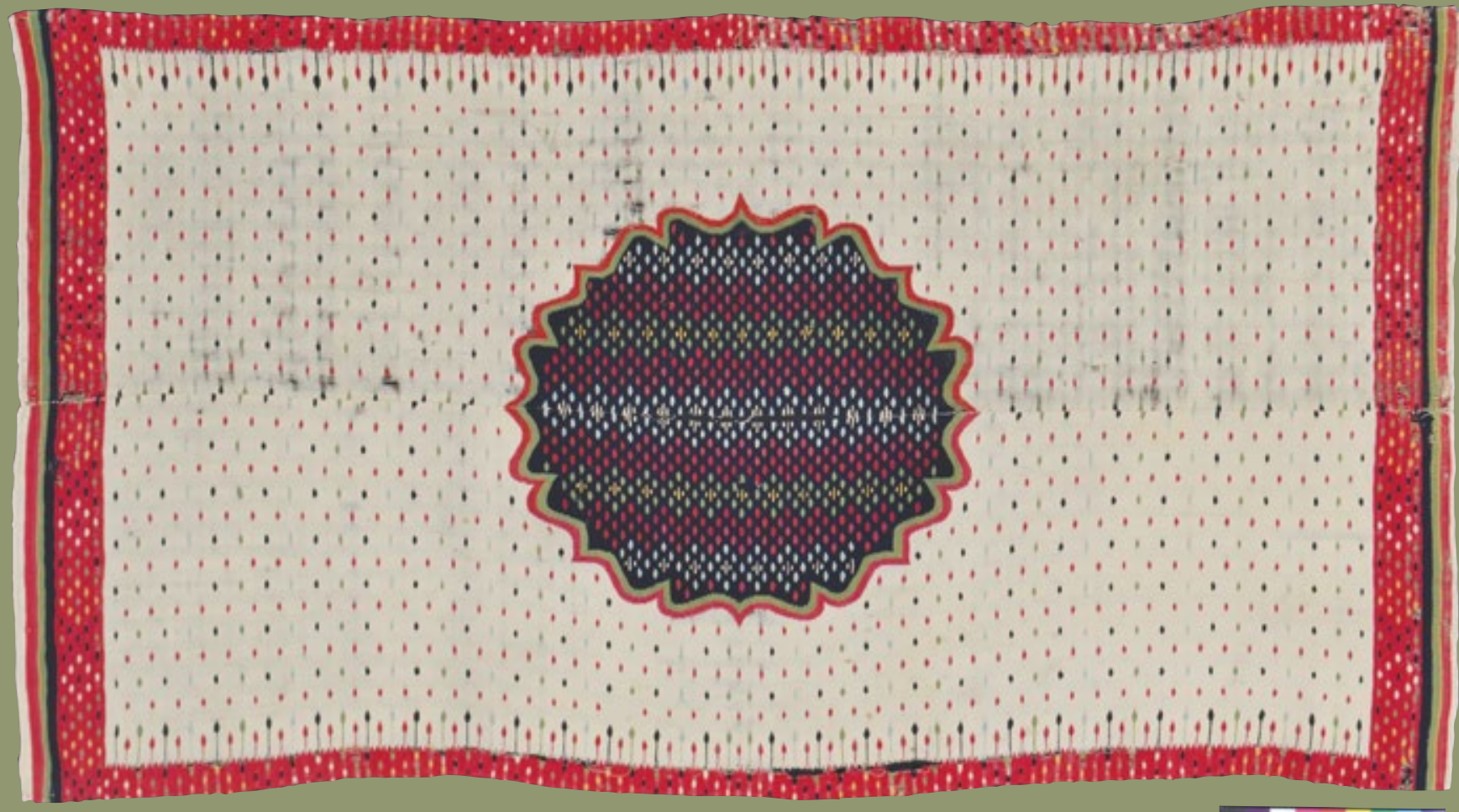

FIGURA 1. El sarape de Saltillo donado por la familia Morrow, pieza perteneciente a la colección de la Subdirección de Etnografía, MNA-INAH (Fotografía: Marilyn Ortiz, Valeria Carrillo y María del Carmen Tostado 2013; cortesía: ENCRyM-INAH y MNA-INAH).

FIGURA 2. Detalle del medallón festoneado del sarape, colección de la Subdirección de Etnografía, MNA-INAH (Fotografía: Marilyn Ortiz, Valeria Carrillo y María del Carmen Tostado 2013; cortesía: ENCRyM-INAH y MNA-INAH).

embargo, los motivos ornamentales que lo conforman distan mucho de aquellos rombos, flequillos y conjuntos de franjas de colores altamente contrastantes que, como lo señala Leal (2010:06-107) caracterizan a los diseños convencionales o tradicionales de los populares sarapes.

Materialidad e historia de vida

Las coloridas espigas y motas ahusadas, el fondo claro y el medallón festoneado del sarape en cuestión son elementos inusitados que, ciertamente, ponen de manifiesto su rareza (Figuras 2 y 3). Su diseño es el resultado sincrético de un conjunto de saberes lejanos y locales ma-

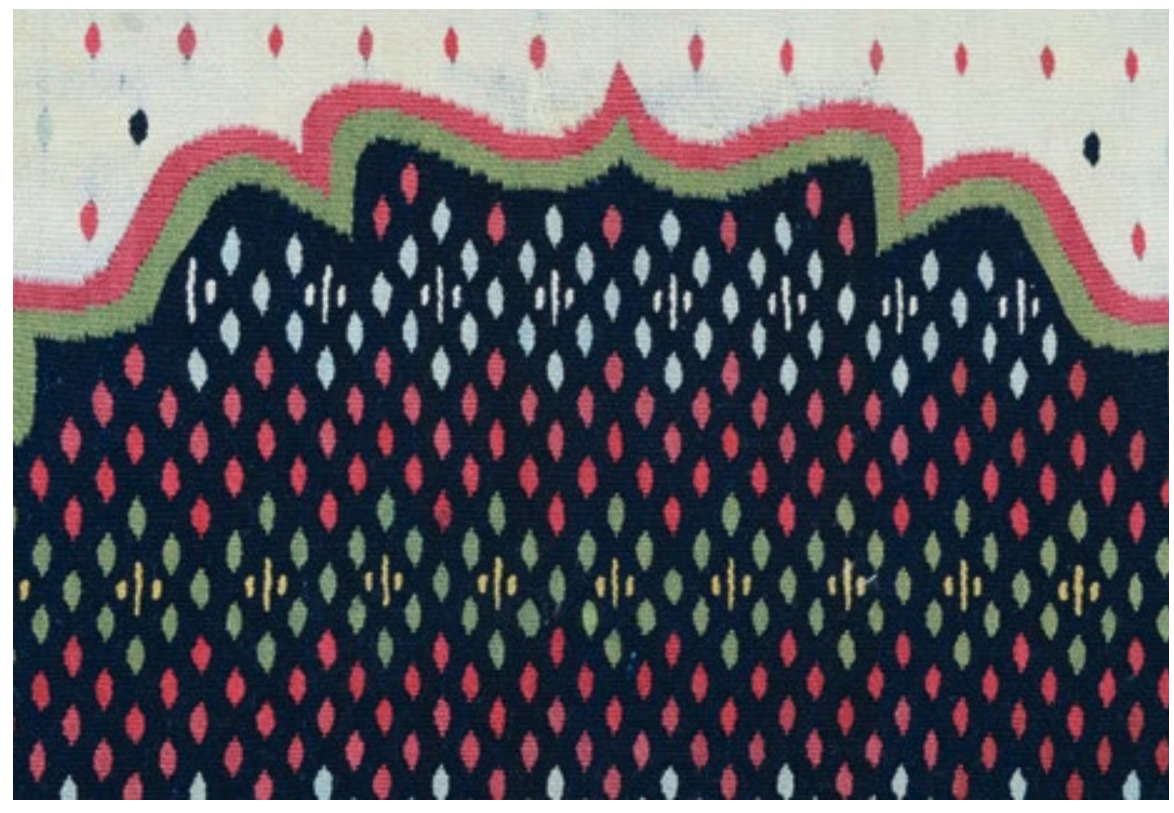




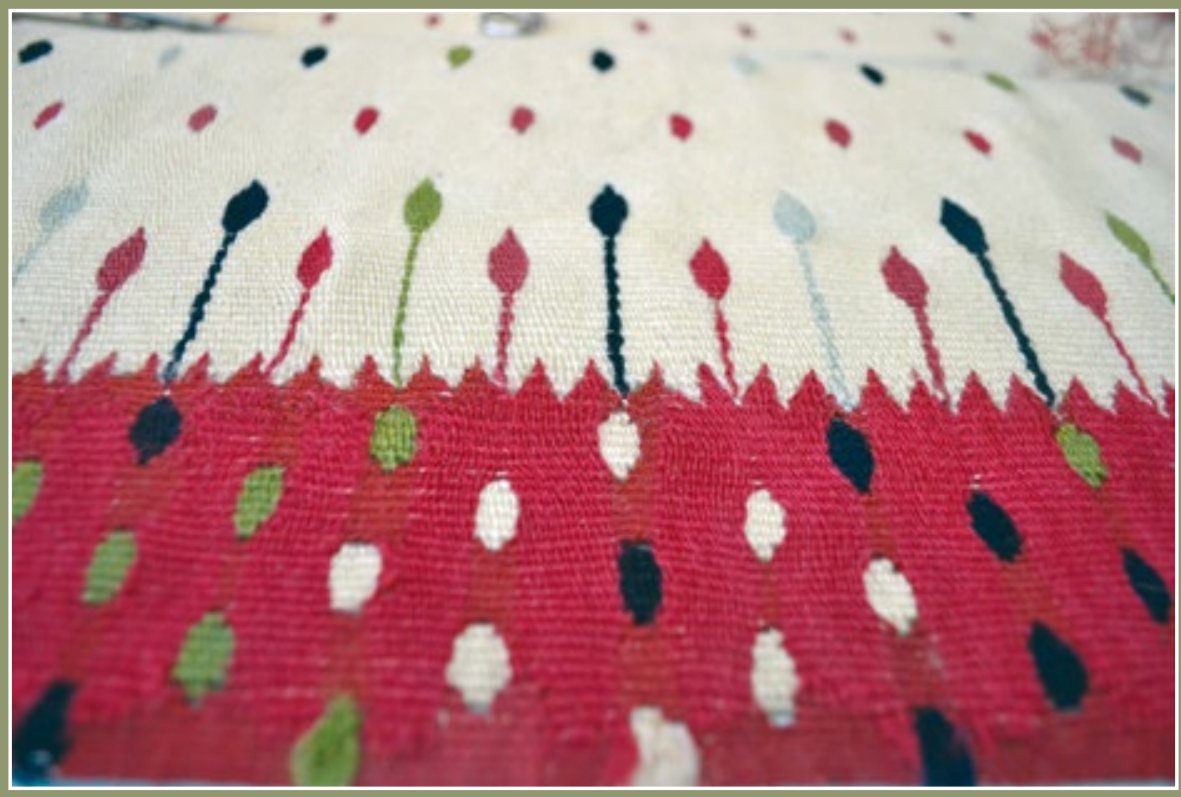

FIGURA 3. Detalle de espigas ahusadas del sarape, colección de la Subdirección de Etnografía, MNA-INAH (Fotografía: Marilyn Ortiz, Valeria Carrillo y María del Carmen Tostado 2013; cortesía: ENCRyM-INAH).
FIGURA 4. Dwight E. Morrow, embajador $>$ de Estados Unidos en México, con su esposa e hija, retrato. (Fotografía: Anon, ca. 1927; cortesía: Sistema Nacional de Fototecas; Instituto Nacional de Antropología e Historia (Sinafo-INAH), número de inventario 22856). terializados en su entramado: como lo señala Jorge Gómez Poncet (Leal 2010:100), el alma de algodón en las urdimbres recuerda el pasado mesoamericano de México, las tramas de lana remiten a los aportes materiales traídos por los españoles, mientras que el medallón festoneado evoca un imaginario morisco que vincula esta obra con una tradición textil nacida en el poblado de Serab, o Serapi (de ahí su denominación: sarape), en lo que hoy es Irán (Armella de Aspe y Castelló Yturbide 1989:105).

Si la factura y el diseño hacen de este sarape un textil extraordinario, la escasez de datos sobre sus orígenes es fuente de curiosidad. Esto motivó una investigación sobre su materialidad e historia de vida -que fue aproximada-por medio de observación directa, algunas pruebas de laboratorio, indagación documental, y la consulta con diversos especialistas, la cual generó importantes conocimientos acerca de la pieza ${ }^{2}$, lo que confirma el potencial de investigación de la disciplina de la con-

${ }^{2}$ Los resultados generales de este trabajo se reportaron en STCRT 2013. servación-restauración, en diversos ámbitos, a saber:

En primer término, la caracterización de la técnica de manufactura del sarape permitió, además de problematizar su datación, replantear cuestionamientos sobre la categorización del elemento dentro de la tradición textil artesanal: ciertamente, la clasificación propuesta por Mark Winter y Marta Turok (Turok 2010:70) ubica los sarapes con medallones festoneados, marco circundante y franjas en los extremos - como el que me ocupa- como "clásicos", es decir, producidos entre 1750 y 1860 . Sin embargo, la propia Turok (2010:70) que indica otro de los rasgos de los sarapes de Saltillo de carácter "clásico" es la densidad -es decir, la cuenta de hilos utilizados por pulgada cuadrada-, cuyo rango debe oscilar entre los 60 y 120 hilos en trama y los 18 y 27 en urdimbre, disposición que difiere del caso de estudio en el STCRT, ENCRYM-INAH, cuya densidad aproximada es de 22 tramas por 12 urdimbres en ambos lienzos, lo cual ofrece la posibilidad de que el textil se haya fabricado en una época posterior a
1860 y, por lo tanto, estrictamente no sea posible categorizarlo como "clásico".

Esta consideración ilustra la manera en que la investigación en conservación-restauración, fundamentalmente ceñida a la materialidad de las obras como una fuente de información en sí misma, es capaz de complementar, replantear o enriquecer los estudios de otras disciplinas antropológicas y, por tanto, da sentido a la consulta de literatura y a la discusión con especialistas.

Otro hallazgo significativo, el segundo, sobre el sarape, remitió al tema de su valoración histórica. Efectivamente, indagaciones bibliográficas sugieren una relación relevante entre el significado del textil y su contexto histórico que llevó a principios del siglo xx, a la concepción y articulación del Mexican folk art como una estrategia de gran importancia en el desarrollo de las relaciones políticas entre dos países: México y los EUA.

Como se señaló anteriormente, este sarape fue donado al MNA-INAH por la familia Morrow, concretamente, por los hijos del diplomático Dwight Morrow (González Villarruel 


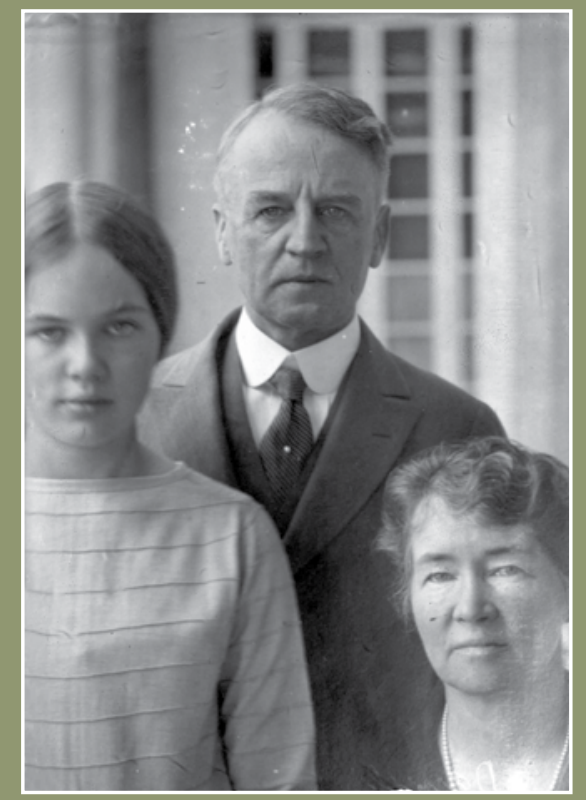

FIGURA 5. El embajador Morrow acompañando al Presidente Calles en un evento oficial (Fuente: Fotografía: Anon. s.f., "Confetti and cheers for Calles and Ambassador Morrow", documento electrónico disponible en [http://radioarquitectura.com/blog/ wp-content/uploads/2011/12/Confetti-and-cheers-for-CallesAmbassador-Morrow-accompanies___-painting-artwork-print11024x719.jpg], consultado en marzo del 2014).

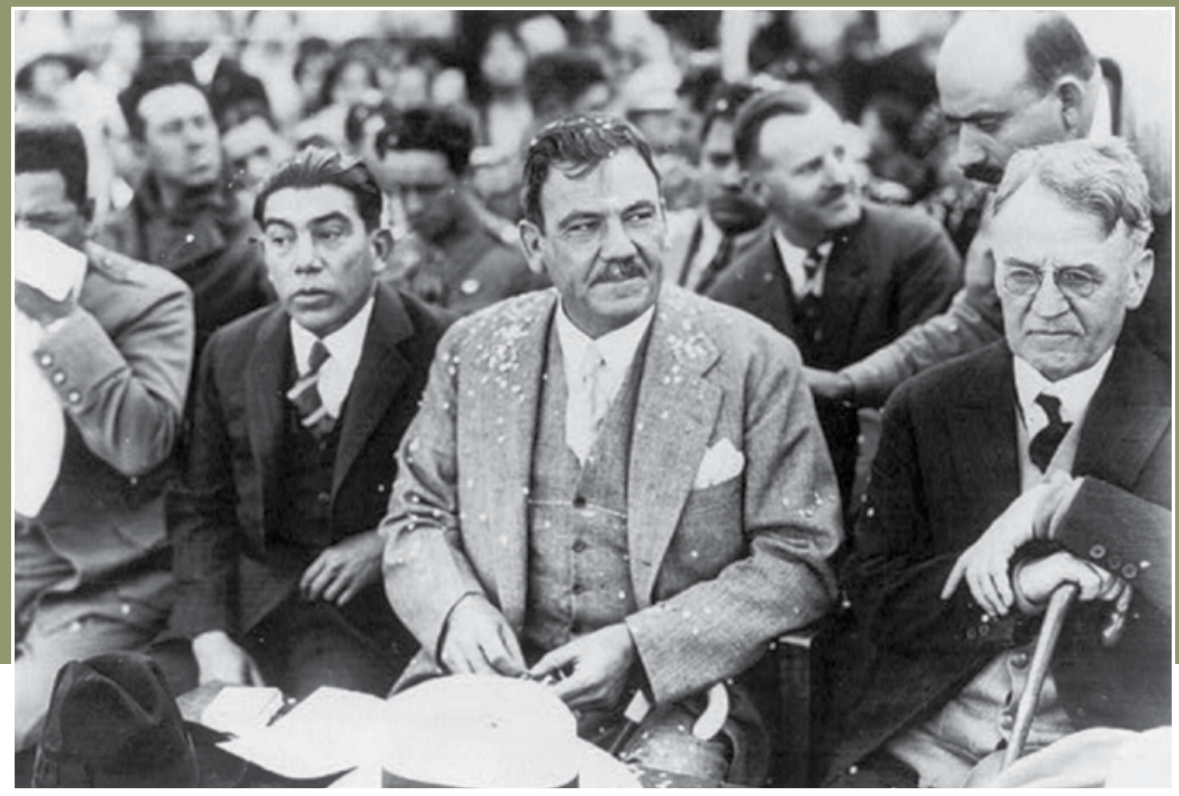

2013). Pero ¿quiénes eran los Morrow? y ¿por qué adquirieron este sarape?

De acuerdo con Delpar (1992:55), en 1927 Dwight Morrow (Figura 4) fue designado embajador de los EUA en México, cargo en el que permaneció durante tres años, a lo largo de los cuales él y su esposa, Elizabeth, se hicieron de una importante colección de objetos, entre ellos, la pieza de análisis.

En aquel entonces, México se encontraba en una notoria inestabilidad político-social, después del largo periodo de lucha revolucionaria, en plena revuelta civil a causa de la Guerra Cristera y en constantes luchas militarizadas por el control del poder Ejecutivo de su gobierno (Meyer 1981:1187-1194). Meyer (1981: 1192) señala que esta situación se agravó en 1928, ya que la sucesión presidencial causó severas disputas entre callistas y obregonistas, mismas que se exacerbaron con el posterior asesinato de Álvaro Obregón. En los años siguientes, la influencia de Plutarco Elías Calles se superpuso a las figuras presidenciales que lo sucedieron, esto le valió el apelativo de
Jefe Máximo, pues controló la posición y/o deposición de diversos candidatos a la presidencia, como: Emilio Portes Gil (1928-1930), Pascual Ortiz Rubio (1930-1932) y Abelardo Rodríguez (1932-1934) (Meyer 1981:1193-1194) (Figura 5).

A este escenario se sumó la hostilidad política entre México y el vecino del norte a raíz de los conflictos territoriales. Recordemos que la secesión de Texas en 1836 y su posterior anexión a los EUA, así como la guerra desatada por el control de más de la mitad de nuestro territorio $y$, finalmente, la venta forzada de La MesiIla, en 1853, fueron conflictos que pusieron de manifiesto el imperialismo estadounidense y generaron una profunda animadversión en México; por si fuera poco, nuestro país volvió a padecer invasiones de ese país en 1914 y 1916 (López 2001:65-66). Como se mencionó anteriormente, poco más de un decenio después de estos sucesos, los Morrow llegaron a México para cumplir funciones diplomáticas.
Stavans (2001:6-8) afirma que Dwight Morrow, consciente de esta animadversión, asumió la tarea de "abrir una amplia línea de diálogo cultural entre las dos naciones": de hecho, su curiosidad y la de su esposa, especialmente respecto de las artes folclóricas y visuales de la nuestra, favorecieron el éxito de aquél como embajador. Se hizo evidente, incluso para los mexicanos nacionalistas, que Morrow había Ilegado para mitigar tensiones, apreciar la cultura mexicana y agradar; sin embargo, lograr la primera meta resultó difícil, mientras que las siguientes fueron mucho más asequibles (Stavans 2001:6-8).

A principios de la década de 1920, cuando las relaciones entre estos dos países eran tensas, algunos políticos estadounidenses que viajaron a México concibieron un discurso sobre la política y la sociedad mexicanas que contrarrestara las críticas del gobierno estadounidense al régimen revolucionario, en el que jugaron un papel muy importante el 
entusiasmo sobre la herencia cultural prehispánica presente en el arte popular y el trabajo de artistas como Diego Rivera y José Clemente Orozco (Delpar 1992: IX-X, 55-90). Ya a finales de esa década, dichas relaciones habían Ilegado a su distensión tanto por cambios en uno y otro países como, de manera singular, por la labor de Dwight Morrow, quien, primero como embajador $y$ en los años posteriores como actor político influyente, profundizó los vínculos culturales entre ambos pueblos (López 2001:69-70): intervino en asuntos como la legislación petrolera, en 1928, y, un año después, tanto en la solución del conflicto cristero como en el apoyo a la facción callista de la clase política (Meyer 1981:1192). Delpar (1992:55) afirma que el interés por la cultura mexicana en los EUA, que alcanzó su punto más álgido durante la crisis económica del 29, no habría florecido sin el mejoramiento de las relaciones diplomáticas.

Así, conforme disminuyó la tensión, el arte y la cultura mexicanos se convirtieron en los principales atractivos para los viajeros de los EUA, quienes avivaron tal flujo de libros, pinturas y diversas obras vinculadas con México que para 1930 éste no sólo disfrutaba de estar en boga en aquel país, el cual se había transformado en puerto de destino de nuestros migrantes culturales (pintores, compositores, actores, entre otros), lo que también contribuyó a este, Ilamémosle súbito, interés por lo mexicano (Delpar 1992: x, 55-90).
Los Morrow emprendieron la aventura de conocer nuestro país a través de su cultura material y se dieron a la tarea de acuñar en el extranjero la idea de éste como un sitio de conocimiento ancestral, para lo cual se sirvieron de estrategias como traer a personajes notables $y$, en su patria, fungir como patrocinadores de algunos mexicanos en la difusión de su trabajo (Danly 2001:7). De hecho, Dwight Morrow financió, a un costo de 12000 dólares de aquel entonces (Delpar 1992:65), los murales que Diego Rivera pintó en el Palacio de Cortés en Cuernavaca, Morelos (Lee 2001:147).

Otra estrategia consistió en edificar una casa en Cuernavaca donde, además de que artistas e intelectuales se dieran cita, se albergara su colección de piezas de arte folclórico mexicano. En este sitio, denominado Casa Mañana, ${ }^{3}$ se reunieron obras de gran singularidad producidas en México, incluido el sarape de Saltillo aquí en estudio (Danly 2001:118-119). Con esta colección los Morrow organizaron diversas exposiciones en museos de su tierra, como la emblemática Mexican Arts en el Metropolitan Museum of Art de Nueva York en 1930 (López 2001:77). Cabe la posibilidad de que este sarape, más de 30 años antes de que se donara al MNAINAH, haya participado en dicha exposición junto con otras obras y propuestas artísticas.

\footnotetext{
${ }^{3}$ Hoy en día restaurante La India Bonita, en la calle Morrow núm. 15-B, en el centro de Cuernavaca, estado de Morelos (México).
}

Delpar (1992:65-66) ilustra cómo Elizabeth Cutter Morrow no sólo fue cómplice de su esposo en la empresa diplomática, sino que tomó iniciativas propias: además de recibir a Diego y Frida —quienes vivieron un año en la Casa Mañana, durante los trabajos de los frescos del Palacio de Cortés-, se entregó a reunir un conjunto de objetos de arte popular mexicano. En su labor, la señora Morrow fue asistida por René d'Harnoncourt, un vienés, artista por vocación, recién llegado a México, con quien llevó a cabo su primera obra $^{4}$ inspirada en nuestro país, The Painted Pig, un libro infantil ilustrado por d'Harnoncourt, cuya publicación fue seguida de importantes actividades para darlo a conocer en los EUA (Delpar 1992:180-181). Los actos promovidos en materia de arte y cultura mexicanos resultaron económicamente tan productivos que para 1931 John D. Rockefeller, Jr., ofreció la suma de 25000 dólares para la Paine Mexican Arts Corporation, dirigida por Frances Paine, Elizabeth Morrow y Abby Aldrich Rockefeller (Delpar 1992:138-139).

Estas estrategias de coleccionismo y difusión acometidas por el matrimonio Morrow encontraron un eco favorable en el contexto intelectual de nuestro país, en el que, ya al concluir la Revolución, artistas y estudiosos mexicanos buscaban afirmarse socialmente definiendo la ca-

\footnotetext{
${ }^{4}$ Publicada en 1930; en 1932, Elizabeth Morrow escribió Casa Mañana y, 30 años después, The Mexican Years: Leaves from the Diary of Elizabeth Cutter Morrow.
} 
FIGURA 6. Reordenamiento de urdimbres, sarape de Saltillo perteneciente a la colección de la Subdirección de Etnografía, MNA-INAH (Fotografía: Marilyn Ortiz, Valeria Carrillo y María del Carmen Tostado 2013; cortesía: ENCRYM-INAH y MNA-INAH).

tegoría de "lo nuestro" a partir de la cultura indígena y campesina (López 2001:72). López (2001:70-71) afirma que el México que fascinó a los Morrow fue aquel que promovían los dirigentes intelectuales posrevolucionarios, es decir, el "México indio".

Los intelectuales posrevolucionarios, pues, en su busca de una cultura distintiva nacionalista alrededor de la cual unir a la población, volcaron su interés en los indios mexicanos y las tradiciones campesinas (López 2001:71), de manera que las actividades de los Morrow a partir de su llegada a México, en 1927, también han de entenderse a la luz de ese contexto intelectual: de hecho, López (2001:73) afirma que las acciones de extranjeros consolidaron los esfuerzos posrevolucionarios del Estado mexicano por legitimarse y promover una identidad nacional unificadora.

Por su parte, Delpar (1992:CIII), quien dio cuenta de la evolución de las relaciones culturales entre los Estados Unidos y México entre 1920 y 1935, afirma que en aquel país nuestra cultura fue diseminada por mexicanos y estadounidenses, y aquellos fueron expuestos a la cultura estadounidense como nunca antes. Las condiciones políticas, económicas e intelectuales que en ambos países crearon un ambiente propicio para el desarrollo de dichas relaciones significaron el regreso a una vida políticamente estable en México después de la agitación revolucionaria, el ascenso económico global de los Estados Unidos tras la Primera Guerra
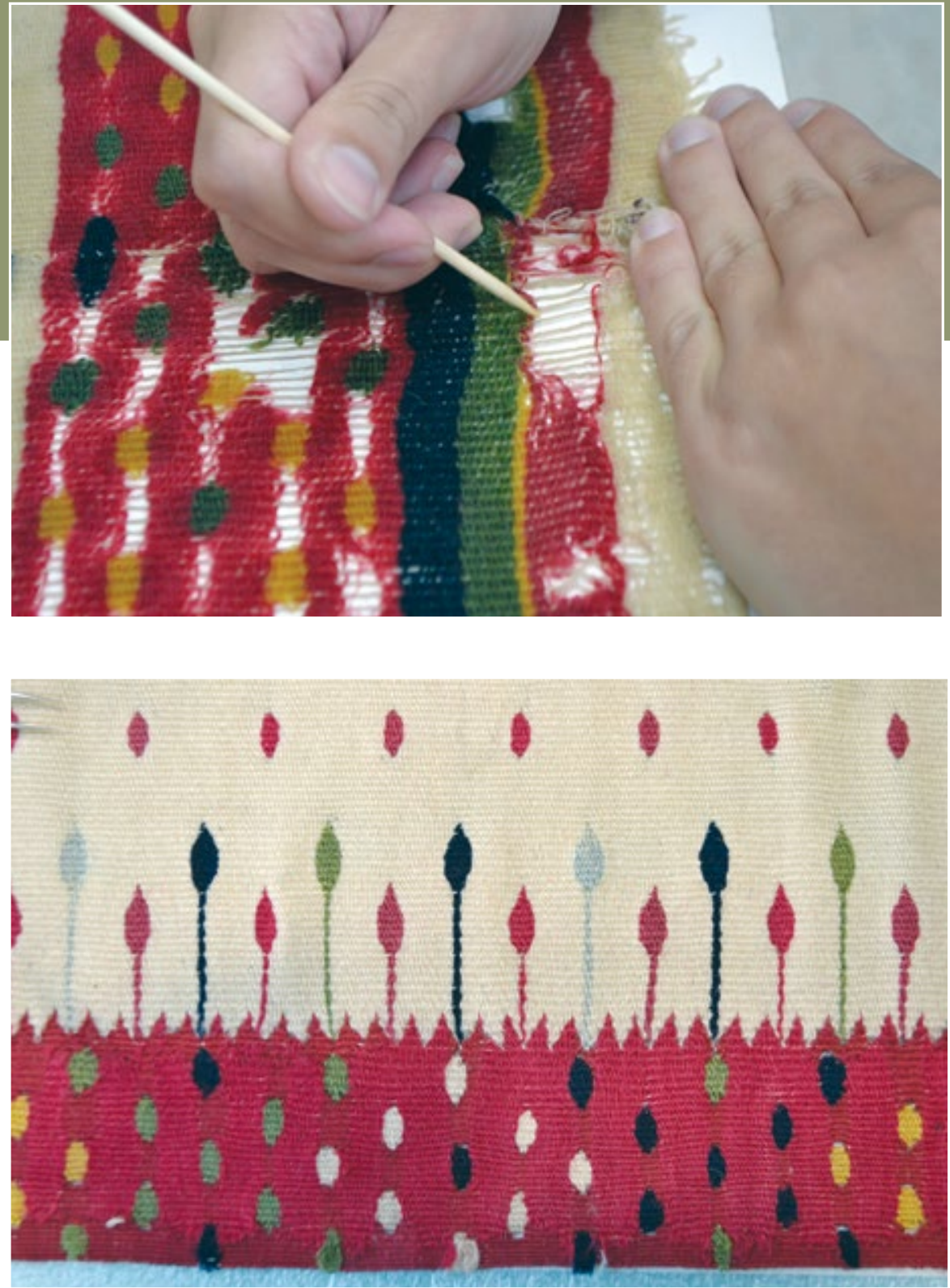

Mundial, y el florecimiento del nacionalismo cultural en los dos territorios.

\section{Conclusiones}

Gracias a la investigación de este sarape realizada en el STCRT, ENCRYM-INAH, fue posible llevar a cabo intervenciones de conservación-restauración que estabilizaron su materialidad y favorecieron su apreciación; esto es, por un lado, las reposiciones de urdimbre dotaron de estructura al sarape, mientras
$\Delta$

FIGURA 7. Detalle de cenefa retejida, sarape de Saltillo de la colección de la Subdirección de Etnografía, MNA-INAH (Fotografía: Marilyn Ortiz, Valeria Carrillo y María del Carmen Tostado 2013; cortesía: ENCRyM-INAH y MNAINAH).

que, por el otro, el retejido lo consolidó y, simultáneamente, restituyó su imagen (Figuras 6, 7 y 8). De esta manera, se protegió el carácter extraordinario de este textil, se preservaron sus valores estético e histórico, y se salvaguardó, en la medida en que se trata de un ejemplar de gran singularidad entre los sarapes de Saltillo, 


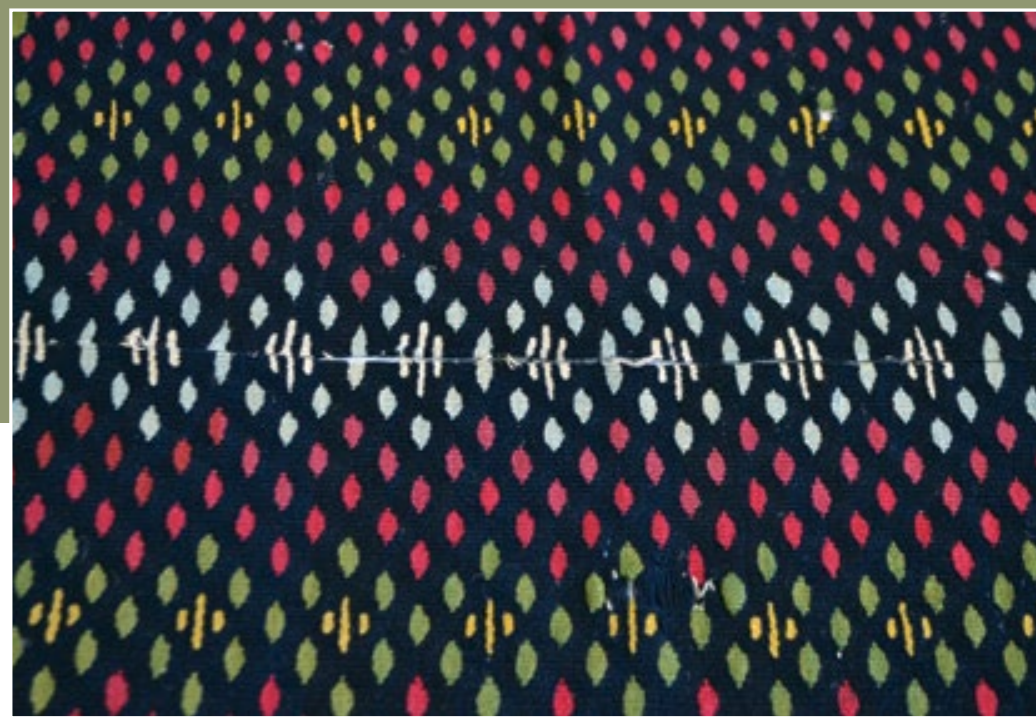

su relevancia e identidad. Finalmente, se recuperaron los conocimientos que dan cuenta de su centralidad como elemento del Mexican folk art y, en ese sentido, como una pieza que formó parte de las estrategias de reconciliación política entre México y los EUA que tuvieron lugar en los albores del siglo XIX. Ese manto de coloridos significados se ha desvelado gracias al cobijo de la conservaciónrestauración.

\section{Agradecimientos}

Agradezco a las licenciadas en restauración Lorena Román Torres, Alejandra Corona, Lilian García-Alonso Alba y Fernanda Martínez Rocha, profesoras del Seminario Taller de Conservación y Restauración de Textiles, ENCRyM-INAH. Brindo un reconocimiento a mis compañeras Valeria Carrillo y María del Carmen Tostado por el trabajo colectivo en la intervención de esta obra. Asimismo, debo gratitud al doctor Alejandro González ViIlarruel, Subdirector de Etnografía, y a la restauradora Sofia Heize MNA-INAH, quienes como parte del proceso de enseñanza-aprendizaje de dicho seminario-taller, nos proporcionaron, a mis compañeras y a mi, datos de suma relevancia para comprender la importancia del sarape que aquí nos ocupa, y a partir de ello emprender su investigación y conservación-restauración.

\section{Referencias}

APA (ed.)

2010 Manual de publicaciones de la American Psychological Association, México, El Manual Moderno/American Psychological Association (APA).

Armella de Aspe, Virginia y Teresa Castelló Yturbide

1989 Rebozos y sarapes de México, México, Gutsa.

Danly, Susan

2001 "Casa Mañana", en Susan Danly (ed.), Casa Mañana:
The Morrow Collection of Mexican Arts, catálogo de exposición, Albuquerque, University of New Mexico Press, 115131.

Delpar, Helen

1992 The Enormous Vogue of Things Mexican: Cultural Relations Between the United States and Mexico, 1920-1935, Tuscalosa, The University of Alabama Press.

González Villarruel, Alejandro

2013. Comunicación personal. Plática en el marco de proceso de enseñanza-aprendizaje del Seminario-Taller de Conservación y Restauración de Textiles de la Escuela Nacional de Conservación, Restauración y Museografía, Instituto Nacional de Antropología e Historia (STCRT, ENCRyM-INAH).

Leal, Gabriel

2010 "Entre tramas y urdimbres: técnicas", en Sarape de Saltillo, México, Instituto Coahuilense de Cultura/Conaculta, 100-119.

Lee, Anthony

2001 "Pintando la chispa de la esperanza: 'Historia de Cuernavaca y Morelos', de Diego Rivera", en Susan Danly (ed.) 2001:147-155.

López, Rick A.

2001 "Los Morrow en México: política nacionalista, patrocinio extranjero y la promoción de las artes populares mexicanas", en Susan Danly (ed.), 2001:65-80.

Meyer, Lorenzo

1981 "El primer tramo del camino", en Historia general de México, t. 2, México, El Colegio de México, 1183-1271.

Stavans, Ilan

2001 “Introducción”, en Susan Danly (ed.), 2001:5-10. STCRT

2013 "Sarape. Informe de los trabajos de Restauración y Conservación realizados", mecanoescrito, ENCRyM-INAH.

Turok, Marta

2010 "Consolidación de una prenda nacional", en Sarape de Saltillo, México, Instituto Coahuilense de Cultura/Conaculta, 61-85. 


\section{Resumen}

Los textiles, como todo bien cultural, están constituidos por una trama de historia y creatividad. El sarape de Saltillo documentado en este artículo ha sabido guardar hasta ahora los secretos de su singularidad, no sólo los relativos a su técnica de manufactura y diseño sino, especialmente, una dimensión sociopolítica y diplomática: fue testigo de la conciliación cultural entre México y los Estados Unidos que tuvo lugar en la década de 1930. El acercamiento entre ambos países se tejió, como este textil, urdiendo ideas e iniciativas, una de las cuales fue, precisamente, la de Dwight y Elizabeth Morrow, al adquirir este textil cuyos rasgos dan cuenta de su inusitado valor.

\section{Palabras clave}

arte popular mexicano; Dwight Morrow; medallón festoneado; relaciones México-Estados Unidos; sarape de Saltillo

\section{Abstract}

Textiles, as any other cultural artifact, weave history and creativity. This paper records the history of a sarape form Saltillo, that has hitherto kept the secrets of its singularity, not only related to its manufacture technique and design, but, particularly to a political, social and diplomatic dimension: it was witness to the cultural conciliation between Mexico and the United States of America during the 1930's. Like the warp and woof in this textile, the approach of these two nations interwined of ideas and acts; one of them was that of Dwight and Elizabeth Morrow in acquiring this textile featuring unusual values.

\section{Key words}

Mexican folk art; Dwight Morrow; garland medallion; Mexico-United States Relations; Saltillo sarape

Título en inglés: Under the cover of a sarape: colors and international conciliations through folk art 